\title{
O BRASIL NA ALCA: AVALIAÇÃO DOS EFEI- TOS DE DUAS PROPOSTAS DE ADESÃO ${ }^{1}$
}

\author{
Viviani Silva Lirio $^{2}$ \\ Antônio Carvalho Campos ${ }^{3}$
}

Resumo - Neste estudo, buscou-se quantificar e avaliar os efeitos da adesão do Brasil à Área de Livre Comércio das Américas (ALCA) sobre indicadores selecionados, tomando-se por base dois cenários analíticos: um que sustenta a adesão individual dos países ao acordo, e outro que prevê a adesão em bloco dos países membros do Mercosul. Para isso, foi construído um modelo de equilíbrio geral, nos moldes do Mathematical Programming System for General Equilibrium - MPSGE, que permitiu, a partir das simulações realizadas, atingir os objetivos da pesquisa. Os resultados encontrados indicam que, para o Brasil, a adesão em bloco mostra-se mais satisfatória, com efeitos sobre renda e consumo bem mais expressivos do que no cenário que prevê a adesão individual. Os efeitos sobre o investimento mostraram-se praticamente equivalentes, e a receita governamental foi substancialmente maior no segundo cenário. Assim, os resultados mostram que a opção pela adesão conjunta, fundamento da proposta brasileira, sustenta-se não apenas no discurso da sobrevivência do Mercado Comum do Sul - Mercosul, mas também em perspectivas mais favoráveis à economia nacional.

Palavras-chave: ALCA, MERCOSUL, modelos aplicados de equilíbrio geral.

\section{Introdução}

Os processos de desregulamentação comercial entre países ainda persiste como tema freqüiente nos fóruns de debate sobre os rumos da economia internacional. Nesses espaços, as vantagens e limitações dos variados formatos de flexibilização propostos convergem para a idéia de que existe um conjunto tão vasto de opções quanto de requerimentos, $o$ que estimula, continuamente, a busca de novas maneiras de estruturar esses procedimentos.

\footnotetext{
${ }^{1}$ Recebido em 02/07/2004. Aceito em 02/09/2004.

${ }^{2}$ Professora da Universidade Federal de Viçosa. E-mail: vslirio@ufv.br

${ }^{3}$ Professor da Universidade Federal de Viçosa. E-mail: accampos@ufv.br
} 
Concomitantemente, torna-se cada vez mais importante o desenvolvimento de modelos econômicos que sejam capazes de antever os principais efeitos da ampliação da integração de mercados entre diferentes nações. Dentre as várias propostas metodológicas que visam a esse objetivo, destacam-se os Modelos Aplicados de Equilíbrio Geral-MAEGs, dada sua versatilidade e adequação.

Assim, o objetivo central deste trabalho é quantificar e analisar os efeitos da implantação da Área de Livre Comércio das Américas (ALCA) sobre algumas variáveis macroeconômicas selecionadas (Índice de Preços ao Consumidor, Investimento, Receita Governamental, Renda Familiar, Consumo Alimentar e Consumo Total das Famílias), tendo por cenários analíticos: (a) a adesão individual dos países ao acordo; e (b) a integração em bloco dos integrantes do Mercado Comum do Sul Mercosul.

Espera-se que a comparação dos resultados dessas simulações possa contribuir para o debate desse tema, hoje amplamente discutido tanto na academia quanto nos meios empresariais brasileiros.

Este artigo está organizado em cinco partes. Além desta introdução, a segunda trata dos aspectos básicos a serem considerados quando da análise dos efeitos de processos de integração comercial. A terceira aborda os principais aspectos metodológicos considerados; e a quarta reporta-se à discussão dos principais resultados encontrados. $\mathrm{Na}$ parte final, detalham-se as principais conclusões encontradas no estudo.

\section{Considerações sobre os processos de abertura comercial e formação de blocos de comércio}

Ao analisar as diferentes etapas constitutivas dos processos de abertura e integração comercial entre as nações, é possível notar que a busca de um modelo ideal para o intercâmbio externo é antiga. Na verdade, a idéia fundamental de que um padrão de comércio não regulamentado 
constitui um fundamento importante para o desenvolvimento - base das teorias pioneiras em comércio internacional - sempre foi acompanhada do exercício de criação de diversas medidas, mais ou menos ostensivas, de proteção comercial.

Como resultado, desenvolveram-se, concomitantemente, duas propostas de intercâmbio comercial: o multilateralismo e as uniões regionais de comércio - preocupação central deste estudo - sendo essas últimas, em muitos casos, apenas uma proposta inicial, com vistas no aprofundamento futuro da integração.

Assim, resguardadas as devidas especificidades de análise, a base teórica do livre comércio internacional acabou por servir de base à construção de modelos mais específicos, e a integração econômica passou a ser entendida como o processo de eliminação de fronteiras e barreiras de natureza econômica existentes entre dois ou mais mercados.

As décadas de 60 e 70 foram pródigas na ampliação e no refinamento da estrutura analítica da clássica teoria das uniões alfandegárias, visto que se buscou compreender, com base em extensões teóricas, as razões que justificariam o surgimento dos acordos de integração regional de comércio. Nesse sentido, as questões fundamentais a serem analisadas consistiam no entendimento de quais fatores seriam capazes de motivar os governos nacionais a adotarem esquemas distintos do livre comércio e, além disso, de que forma a criação dos blocos poderia favorecer a superação de obstáculos domésticos e estruturais ao crescimento econômico.

De fato, a questão central encontra-se na idéia de que o livre comércio é um regime que sempre traz efeitos econômicos e sociais superiores a qualquer outro esquema comercial. Assim, dada a impossibilidade de se tomar a melhoria na alocação de recursos como justificativa única para o estabelecimento de esquemas de liberalização restritos a determinado grupo de países, torna-se necessário verificar quais outras fontes potenciais de benefícios justificariam a criação de uniões alfandegárias. Nesse contexto, dois fatores são relevantes: os efeitos dinâmicos da 
integração e as alterações nos termos de troca. Ademais, segundo Baptista (1993:39),

"a despeito da importância da formação dos blocos de comércio como forma de incremento do poder de barganha dos países membros frente a outros parceiros, esse assunto é, via de regra, pouco considerado pela clássica teoria da integração e suas derivações que pressupõem, quase sempre, estruturas tarifárias idênticas para os países, antes de iniciado o processo de integração. $\mathrm{Na}$ realidade, quanto maior for o número de países associados e suas respectivas participações no cenário internacional, mais amplo tende a ser o poder de pressão junto aos demais parceiros comerciais, no sentido de alcançar concessões, por exemplo, de acesso privilegiado a mercados. A contrapartida geralmente exigida do grupo integrado comercialmente é a determinação de um consenso a respeito da melhor política comercial a ser seguida, o que constitui tarefa mais árdua quanto maior for o número de países envolvidos no processo de constituição do bloco."

Para o referido autor, isso é essencialmente importante, em virtude de as políticas comerciais, em particular as práticas tarifárias, terem impacto incisivo no bem-estar dos cidadãos, por meio de seus efeitos sobre a distribuição de renda. Como as tarifas representam benefícios para alguns agentes econômicos, é compreensível que estes estejam interessados na sua manutenção. Todavia, vale ressaltar que o efeito final global da prática tarifária sobre a renda nacional é quase sempre negativo, pois os ganhos decorrentes da melhoria nos termos de troca, normalmente, não compensam os custos da proteção.

Vale considerar todavia que, além dos citados efeitos sobre preços internos, produção e consumo domésticos, volume de compras e vendas externas, modificação nos termos de troca e remuneração dos fatores de produção (distribuição funcional de renda), existem outros dois impor- 
tantes reflexos derivados da imposição de uma tarifa sobre as importações, quais sejam, redução potencial do nível de desemprego pelo estímulo à produção interna e melhoria do saldo da balança comercial.

Ainda que não se considere esse o método mais eficiente ${ }^{4}$, um país poderia tentar o uso de imposições tarifárias como mecanismo de aumento do produto doméstico pela restrição da concorrência externa, com conseqüente expansão na absorção de mão-de-obra. Contudo, diversos fatores poderiam interferir nesse processo, anulando ou modificando os efeitos potenciais esperados, como seria o caso de alterações tecnológicas que envolvem o padrão de demanda de trabalho para determinado nível produtivo. $\mathrm{O}$ efeito sobre a balança comercial, por sua vez, é ainda mais dúbio - apenas se as conseqüências da proteção forem pequenas, ou seja, se o aumento na renda nacional não repercutir negativamente no aumento das importações, e se não houver retaliação dos parceiros comerciais, haverá melhoria no saldo comercial externo.

Todavia, é imprescindível considerar que outra questão, igualmente relevante, remete às dificuldades de mensurar os custos e benefícios do comércio integrado entre parceiros. Segundo Correa (1993), o surgimento de imperfeições de mercado, decorrentes, por exemplo, de inovações tecnológicas e de economias de escopo, pode criar assimetrias na apropriação dos ganhos advindos da integração, permitindo que a formação de um bloco comercial gere, ao mesmo tempo, ganhos de bem-estar social a determinado membro e prejuízos a outro.

Por outro lado, a especialização intra-industrial e a geração de economias de tamanho permitiriam que mesmo países com estruturas industriais concorrentes, caso do Brasil e dos EUA, em alguns setores da economia, pudessem auferir benefícios de um processo de integração, o que faria com que a instituição de áreas de livre comércio ou de uniões aduaneiras resultasse em ampliação de mercado capaz de estimular a eficiência produtiva e modificar até mesmo o padrão de inserção internacional das economias envolvidas, principalmente nos casos em que predo-

${ }^{4}$ Políticas fiscais e monetárias seriam mais eficazes. 
minassem as estruturas industriais oligopolísticas, nas quais as economias de escala desempenham papel preponderante.

Nessa visão, no caso particular da ALCA e mais especificamente da integração das economias brasileira e norte-americana, é de extrema relevância inferir se os agentes do parque produtivo nacional, principalmente os ligados ao complexo agroindustrial brasileiro, bastante sensível ao processo de desgravação, estão aptos a aproveitar as oportunidades de uma integração regional desse porte e, simultaneamente, a se adaptarem aos novos padrões tecnológicos e concorrenciais que estarão vigentes após a celebração do acordo.

\section{Metodologia}

A estrutura dos Modelos Aplicados de Equilíbrio Geral (MAEG) prevê a construção prévia de uma Matriz de Contabilidade Social - MCS, que representa, em última instância, uma extensão da estrutura fundamental da MIP, ampliada para a contemplar todo o fluxo circular da economia. Assim, a MCS representa, de forma estilizada, a totalidade dos fluxos de renda em um sistema econômico (Najberg et al., 1995).

Naturalmente, o nível de agregação utilizado deve atender ao escopo analítico individual de cada pesquisa, com vistas em permitir a realização de inferências, com maior grau de profundidade e precisão. Definida e efetuada a agregação desejada, a etapa seguinte consiste em transformar os dados brutos em tabelas organizadas de coeficientes, que serviram de base ao modelo. Esse processo envolve a opção por dois sistemas de cálculo: um baseado nas matrizes produto x produto, outro associado às matrizes atividade $\mathrm{x}$ atividade, em que o primeiro prioriza questões tecnológicas e o segundo, as relações intersetoriais. Neste estudo, a opção recaiu na segunda abordagem, e o procedimento metodológico empregado para as "quebras" de linhas e colunas foi o mesmo adotado em Lemos (1995). 
Na forma matricial, essa decomposição implica a substituição do setor considerado $\left(\mathrm{x}_{\mathrm{a}}\right)$, no vetor coluna de produto $(\mathrm{x})$, pelo número correspondente de novos elementos $\left(\mathrm{x}_{\mathrm{i}}\right)$, sendo que nesta pesquisa foi necessária a decomposição do setor agropecuário em 11 novas atividades. A notação desse processo, portanto, pode ser explicitada da seguinte maneira:

$$
\mathrm{x}_{\mathrm{a}}=\sum_{\mathrm{j}=1}^{\mathrm{n}} \mathrm{w}_{\mathrm{aj}}+\mathrm{f}_{\mathrm{a}}
$$

que resulta em

$$
x_{a}=\sum_{i=1}^{11} x_{i}=\sum_{i, j=1}^{11, n} w_{i j}+\sum_{i=1}^{11, n} f_{i}
$$

em que $\mathrm{x}_{\mathrm{a}}$ é o produto da atividade agropecuária; $\mathrm{w}_{\mathrm{aj}}$ é igual aos $\mathrm{n}$ elementos da demanda intermediária de $\mathrm{x}_{\mathrm{a}} ; \mathrm{f}_{\mathrm{a}}$, demanda final da atividade agropecuária; $x_{i}$, produto dos $\mathrm{i}$ novos elementos; $\mathrm{w}_{\mathrm{ij}}$, $\mathrm{n}$ elementos da demanda intermediária para $\mathrm{x}_{\mathrm{i}}$; e $\mathrm{f}_{\mathrm{i}}$, demanda final das $\mathrm{i}$ novas atividades.

Dessa maneira, a atividade agropecuária foi substituída por um conjunto de 11 novas atividades, ou seja, 11 novas linhas na matriz de produção (M) e 11 novas colunas na matriz de absorção (S). Esquematicamente, tem-se, então,

$$
\begin{aligned}
& \sum_{j=1}^{n} m_{a j}=\sum_{i, j=1}^{11, n} m_{i j} \text { na matriz } M, \\
& \sum_{j=1}^{n} m_{j a}=\sum_{i, j=1}^{11, n} m_{j i} \text { na matriz } S,
\end{aligned}
$$

em que $m_{a j}$ é o elemento $\mathrm{j}$ dos produtos produzidos pela atividade agropecuária; e $m_{\mathrm{ij}}$, elemento $\mathrm{j}$ produzido por cada nova atividade desdobrada. 
Via de regra, as soluções de modelos aplicados de equilíbrio geral requerem algoritmos específicos que permitem a resolução de amplos sistemas de equações lineares e, ou, não-lineares. Na elaboração do exemplo prático desenvolvido neste capítulo, utilizou-se, como referência, um modelo de equilíbrio geral nos moldes do Mathematical Programming System for General Equilibrium - MPSGE5 ${ }^{5}$, um sistema de programação matemática desenvolvido pelo professor Thomas Rutherford, do Departamento de Economia da Universidade do Colorado. Esse sistema permite a resolução de um conjunto de equações não-lineares, normalmente restritas às formas funcionais CES e CET e suas variações: CobbDouglas, para os casos de elasticidade de substituição unitária e Leontief, para os de elasticidade de substituição nula.

Segundo Showen e Whalley (1998), as principais restrições a serem consideradas na determinação das formas funcionais referem-se ao fato de que elas devem ser consistentes com a aproximação teórica utilizada e, ao mesmo tempo, analiticamente tratáveis. Tais restrições explicam, em boa parte, as limitações na escolha das formas funcionais, que acabam circunscritas a representações bastante conhecidas, como a Constat Elasticity of Substituition (CES) ${ }^{6}$. No caso deste estudo, optou-se pelo uso da CES, tanto para a demanda quanto para a produção, em virtude de suas propriedades ${ }^{7}$.

No modelo utilizado, os agentes que atuam na produção são maximizadores de lucro e buscam a otimização, levando em conta as restrições de tecnologia e de recursos. A estrutura tecnológica, com base em funções CES nested, considera funções de produção, do tipo Leontief, na combinação inicial de capital e trabalho, permitindo, para níveis mais elevados, algum grau de substitutibilidade entre trabalho qualificado e não-qualificado. Os insumos intermediários utilizados na indústria representam, em alguns casos, combinações do tipo Leontief, e, em

\footnotetext{
${ }^{5}$ Maiores informações em Rutherford (1995).

${ }^{6}$ Para construção das funções de disponibilidade interna, que, por basear-se na pressuposição de Armington, prevê o uso de uma elasticidade de transformação, foi utilizada a forma funcional Constant Elasticity Transformation (CET).

${ }^{7}$ Analogamente, a CES foi usada, como forma funcional, nas equações de importação (demanda doméstica importados) e exportação (produção doméstica de bens comercializados no exterior).
} 
outros, permite-se a substituição de fatores de acordo com suas elasticidades de substituição.

Para as famílias, o delineamento dá-se de acordo com a propriedade dos fatores de produção ${ }^{8}$. Assim, a primeira distinção feita separa as famílias em grupos (se necessário) e subgrupos (por exemplo, em níveis de renda, baseados em estratos salariais). Considera-se que o fator trabalho (qualificado ou não) seja móvel entre os diferentes setores da economia e que sua oferta seja fixa.

No que se refere à demanda, esta é segmentada em categorias. Os bens de consumo final são demandados pelas famílias, pelo governo, pelos investimentos e pelo setor externo. Os consumidores irão maximizar utilidades modeladas em equações do tipo CES nested, considerando suas restrições orçamentárias. Vale ressaltar que as unidades familiares tendem a possuir um padrão razoavelmente estável de consumo, de forma que as eventuais oscilações na renda repercutem em retrações/expansões na poupança. Cada consumidor parte de determinado orçamento, que corresponde à renda disponível, igual ao valor da venda dos serviços de fatores mais as transferências governamentais e externas, deduzidos os impostos. A partir desse ponto, a maximização da utilidade do consumidor ocorre em etapas: no primeiro momento, ele opta por demanda presente ou futura (poupança), desconsiderando a possibilidade de alteração nos preços; em seguida, decide dividir o consumo presente entre lazer e aquisição de bens e outros serviços, alimentares ou não. Assim, ao subtrair os valores destinados à poupança e ao lazer do montante inicial de renda disponível, tem-se o total de recursos destinados ao consumo presente em bens e serviços.

Por fim, no que se refere à poupança e ao investimento, pressupõe-se que a poupança do setor privado seja apenas um resíduo do consumo e que o investimento seja totalmente financiado pelo somatório das poupanças privadas, governamental e externa. Quanto ao setor externo, admite-se que o país venda produtos diferenciados no mercado externo

${ }^{8} \mathrm{O}$ detalhamento familiar empregado foi adaptado de Brandão et al. (1994) e detalhado segundo os propósitos do estudo. 
e que a função de demanda de importações tenha elasticidade-preço finita. Os bens domésticos e os internacionais não são, necessariamente, substitutos perfeitos (pressuposição de Armington); nesse caso, considera-se a maior parte dos bens transacionáveis como uma mercadoria composta, que é função de agregação, do tipo CES, de bens importados e produzidos domesticamente.

\section{Resultados e discussão}

Essa seção discute os principais resultados obtidos dos cenários analíticos propostos, em que o primeiro se refere à adesão individual de cada país à ALCA e o segundo, à adesão em bloco (proposta brasileira).

A matriz de contabilidade social, utilizada como principal fonte de dados para construção do modelo, refere-se à economia brasileira do ano de 1999 e foi obtida da atualização dos dados básicos da matriz de insumoproduto, de 1995.

Importa considerar que, antes da construção do modelo básico (algoritmo), foi necessária a obtenção dos efeitos da desgravação tarifária para a consolidação da ALCA por meio de outro software, o Global Trade Analysis Program - GTAP, desenvolvido por Thomas Hertel no ano de 1992. Esse aplicativo, que possui uma base de dados bastante extensa, permite, mediante suas relações, quantificar os efeitos de processos de integração comercial sobre diversas variáveis.

Todavia, pelas suas características fundamentais, o GTAP não permite o detalhamento necessário aos propósitos deste trabalho, razão pela qual foi utilizado apenas como ferramenta intermediária. O modelo construído posteriormente e que foi a base para as simulações realizadas é composto de quatro estruturas básicas: 21 categorias para bens transacionáveis, três consumidores, 81 estruturas de produção ( 21 para bens produzidos domesticamente, 18 para bens importados, 18 de disponibilidade, 13 para bens exportados e 11 para funções de consumo familiar total e alimentar, investimento, poupança do governo e poupança externa) e duas restri- 
ções auxiliares (uma para desemprego e uma relativa ao índice de preços agregado, em nível de consumidor).

4.1. Efeitos da adesão brasileira à Área de Livre Comércio das Américas (ALCA) sobre indicadores macroeconômicos selecionados

A Figura 1 e a Tabela 1 trazem os resultados dos indicadores macroeconômicos selecionados, em ambos os cenários analíticos considerados.

No que se refere ao índice de preços, observa-se que os resultados indicam que a adesão em bloco (proposta brasileira) possui efeito de crescimento nos preços superior ao observado quando da adesão individual dos países ao acordo comercial hemisférico. A justificativa para esse comportamento ascendente dos níveis médios de preços deve-se ao fato de o movimento de crescimento das atividades produtivas ter sido substancialmente inferior ao observado no indicador relativo ao consumo das famílias (Tabela 1), sendo esse acréscimo na demanda das famílias também maior no segundo cenário.

No caso do investimento, observa-se que os valores mantêm-se bastante próximos, o que sugere que ambas as propostas de adesão tenham tido reflexos similares no referido indicador. 


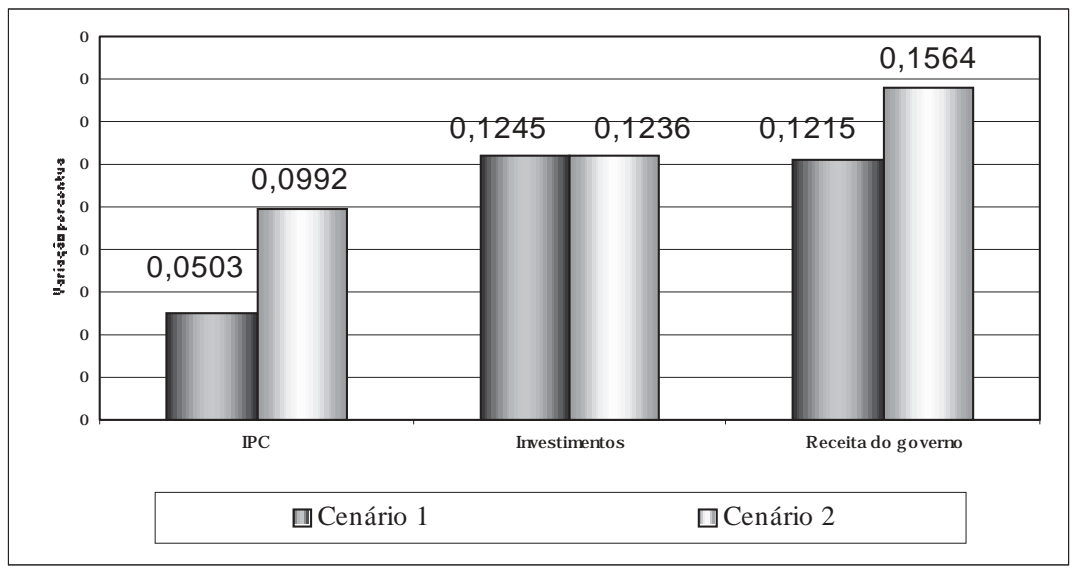

Fonte: Resultados da pesquisa.

Figura 1 - Efeitos da adesão brasileira à ALCA, em cenários distintos, sobre o Índice de Preços, Investimentos e Receita Governamental.

Quanto às receitas do governo, o pequeno incremento observado, que, a princípio, parece contrariar as premissas da Teoria da Integração Comercial, que prega que as receitas das tarifas constituem fluxo importante de recursos para o governo, deriva dos aumentos nas receitas tributárias internas, advindas da imposição de impostos ad valorem sobre o valor da produção setorial e renda familiar (ambos acrescidos), que se sobrepõem às perdas relativas na eliminação progressiva das alíquotas tarifárias.

Esse resultado também foi encontrado - em sentido idêntico, porém em magnitude distinta - em estudo anterior, que buscou analisar os efeitos progressivos da proposta de formação da Área de Livre Comércio das Américas?.

Dando continuidade à análise, os dados da Tabela 1 evidenciam o já referido aumento da renda e do consumo em ambos os cenários simulados. Como é possível observar, houve expansão percentual dos três indi${ }^{9}$ Ver Lirio e Campos (2002). 
cadores considerados e, nos três, os resultados mais expressivos ocorreram quando da consideração da adesão conjunta (Cenário 2) à área de livre comércio hemisférica.

Tabela 1 - Resultados das simulações realizadas para os indicadores renda familiar, consumo das famílias e consumo de alimentos

\begin{tabular}{lcc}
\hline \multicolumn{1}{c}{ Indicador } & Cenário 1 & Cenário 2 \\
\hline Renda familiar & 1,1919 & 2,4236 \\
Consumo das famílias & 1,4364 & 5,2175 \\
Consumo de alimentos & 1,1778 & 2,8473 \\
\hline
\end{tabular}

Fonte: Resultados da pesquisa.

Outra constatação importante refere-se à magnitude dos percentuais encontrados, consideravelmente baixa. A princípio, embora essa possa ser uma informação que desperta surpresa, é preciso considerar que, em se tratando de indicadores como os aqui selecionados, não são esperadas grandes variações percentuais como resultado. Na realidade, magnitudes muito expressivas, derivadas de alterações em variáveis exógenas em modelos estáticos, seriam muito mais questionáveis, uma vez que se trata de um modelo determinístico que considera, dentro das limitações cabíveis, todas as relações intersetoriais da economia brasileira.

Cabe destacar que, dentre os resultados encontrados, os valores obtidos para o consumo das famílias foram muito mais expressivos do que os observados para as demais variáveis (consumo alimentar e renda); apesar de curioso, esse resultado foi compatível com o esperado.

Em economias como a brasileira, cujas estruturas de demanda de bens de maior valor agregado e de bens não-alimentares são muito expressivas, expansões do consumo médio das famílias são esperadas, quando na presença de crescimento da renda. Observa-se que, em ambos os cenários, a variação percentual do consumo alimentar foi um pouco inferior à variação da renda, o mesmo não acontecendo no consumo total das famílias (alimentos e não-alimentos). Ainda assim, uma variação 
próxima a $3 \%$ (caso dos alimentos no segundo cenário) mostra que a adesão ao acordo pode gerar resultados positivos para o bem-estar das famílias brasileiras. Se considerado o consumo total, a expansão supera os $5 \%$, no caso da adesão conjunta ao bloco.

Deve-se destacar contudo que, embora nesta pesquisa não se tenham realizado desagregações nos grupamentos familiares, um procedimento dessa natureza seria interessante para observar a distribuição funcional da renda entre classes de renda, pois serviria para confirmar, ou não, por meio da análise do grau de concentração de renda, se os benefícios aparentemente gerados pela inclusão do Brasil na ALCA seriam sustentados por uma distribuição de recursos mais eqüitativa na economia brasileira.

\section{Conclusões}

Este trabalho objetivou quantificar os efeitos da adesão brasileira à ALCA, em dois cenários distintos - o primeiro que considera a possibilidade de adesão individual (país a país) ao acordo, e o segundo que toma por premissa que os países membros do MERCOSUL realizariam a adesão em bloco (proposta brasileira). Os resultados encontrados indicam que a proposta defendida pelo Brasil é a mais benéfica ao país.

Em todos os indicadores selecionados, os efeitos da integração comercial foram positivos, sendo mais interessantes (e expressivos) os observados na proposta da integração conjunta. Tais resultados, que confirmam um discurso já existente, mostram a importância da inclusão cautelosa do país no acordo, principalmente se considerada a proposta norte-americana de integração individual.

Tendo em vista que os efeitos da ALCA são de dimensões muito amplas e que ainda há um número restrito de pesquisas que buscam, mediante metodologias diversas, quantificar os efeitos da integração, esforços reais de mensuração e divulgação desses impactos são fundamentais para 
o direcionamento político a ser optado. De fato, espera-se, com esse breve trabalho, contribuir com informações mensuráveis para o debate já instalado, no intuito de que sejam aumentadas as possibilidades de entendimento sólido desse tema, tão relevante e crítico para a economia nacional.

\section{Referências bibliográficas}

ÁREA DE LIVRE COMÉRCIO DAS AMÉRICAS - ALCA. [2001]. (www.ftta-alca.org).

BANCO INTERAMERICANO DE DESENVOLVIMENTO - BID. [2001]. (www.iadb.org).

BAPTISTA, E. Dimensão institucional dos processos de integração: as políticas industrial, de concorrência e comercial da Comunidade Européia. Rio de Janeiro: FUNCEX, 1993. (Textos para Discussão, 81).

BRANDÃO, A.S.P., HERTEL, T., CAMPOS, A.C. Distributional implications of agricultural liberalization: a case study of Brazil. In: GOLDIN, I., KNUDSEN, O., BRANDÃO, A.S. (Ed.). Modeling economy - wide reforms. Paris: OECD/Development Centre Studies, 1994. $296 \mathrm{p}$.

CARVALHO, A., PARENTE, M.A., LERDA, S., MIYATA, S. Impactos da integração comercial Brasil - Estados Unidos. Brasília: IPEA., 1999. 62 p. (Textos para discussão, 646).

CASTILHO, M.R. Algumas considerações sobre o uso de modelos computáveis de equilíbrio geral como instrumento de análise do setor externo brasileiro. Rio de Janeiro: Fundação Centro de Estudos do Comércio Exterior/IPEA, 1994. 26 p. (Textos para discussão, 97). 
CONFEDERAÇÃO NACIONAL DA AGRICULTURA - CNA. [2001]. (www.cna-rural.com.br).

CORREA, P.G. Estrutura industrial e comércio exterior: teoria, evidências empíricas e implicações normativas. Rio de Janeiro: UFRJ, 1993. 124 p. Dissertação (Mestrado) - Universidade Federal do Rio de Janeiro, 1993.

HARRISON, G.W., RUTHERFORD, T.F., WOOTON, I. An alternative welfare decomposition for customs unions. Canadian Journal of Economics, v. 26, n. 4, 961-968, 1994.

HERTEL, T.W., TSIGAS, M.E. Structure of GTAP. In: HERTEL, T.W. (Ed.). Global trade analysis: modeling and aplications. New York: Cambridge University Press, 1996.

LEMOS, M.B. Sistema agroindustrial brasileiro: metodologia de identificação dos seus agrupamentos produtivos. Revista Nova Economia, Belo Horizonte, v. 5, n. 2, p. 61-81, 1995.

LIRIO, V. S., CAMPOS, A. C. Do Mercosul à Alca: Impactos sobre as cadeias do Agronegócio Brasileiro. Viçosa: Editora UFV. $204 p$.

NAJBERG, S., RIGOLON, F.J.Z., VIEIRA, S.P. Modelo de equilíbrio geral como instrumento de política econômica: uma análise de câmbio x tarifas. Rio de Janeiro: BNDES, 1995. 24 p. (Textos para discussão, 30).

RAMOS, R.L.O. Uma comparação dos modelos para o cálculo dos coeficientes técnicos diretos de Leontief. Rio de Janeiro: UFRJ, 1997. 200 p. Tese (Doutorado em Engenharia da Produção) - Universidade Federal do Rio de Janeiro, 1997.

SHOVEN, J.B., WHALLEY, J. Applying general equilibrium. 3.ed. Cambridge: Cambridge University Press, 1998. 299 p. 
Abstract - This study has the objective of evaluating the economic effects of the Brazilian integration into the Free Trade Association of Americas - FTAA under two alternative scenarios. In the first, the adhesion of the Brazilian economy would happen as an isolated country. In the second, the joint adhesion of Brazil would follow the rules established for all members of MERCOSUR. The analytical framework is that of an applied general equilibrium analysis which permit the measurement of different impacts of simulations on selected economic indicators. The results point out that the joint adhesion of MERCOSUR countries as an economic block into FTAA, which is the position defended by Brazilian negotiators, is much more beneficial to the Brazilian economy than the integration as an independent country. The impacts of integration in FTAA on the growth of disposable income, taxation, and personal consumption are much higher under the second scenario. Therefore, this study supports the Brazilian posture that the FTAA should not be negotiated with isolated countries but taking into account all the previous agreements prevailing in South America.

Keywords - FTAA, MERCOSUR, Applied General Equilibrium Analysis 
REVISTA DE ECONOMIA E AGRONEGÓCIO, VOL.2, N $N^{o} 3$ 